\title{
Gestão compartilhada da educação: o discurso e as práticas cotidianas no sistema de ensino do Recife
}

\author{
Edson Francisco Andrade*
}

\section{Resumo}

O presente artigo analisa a questão do compartilhamento das decisões no âmbito da gestão da educação pública, problematizando a relação entre o discurso da gestão democrática e as práticas sociais dos conselheiros escolares e dos gestores do Sistema Municipal de Ensino do Recife. Os dados, coletados através de entrevistas e administração de questionários, foram tratados na perspectiva da análise de discurso. O objetivo é cotejar determinadas concepções e caracterizações da gestão compartilhada, presentes na literatura do campo educacional, e nas entrevistas dos sujeitos da pesquisa, com as nuances que envolvem o processo de proposição de políticas educacionais para o município do Recife. Conclui-se que as ações dos sujeitos que poderiam contribuir para a materialização dos princípios democráticos na gestão da educação municipal são desarticuladas ou silenciadas por um conjunto de fatores, entre os quais se destaca a desarticulação entre as instâncias de participação. Isso prova que a dificuldade de participação que freqüentemente é apontada como limitação estritamente da escola, trata-se de um problema que envolve, sobretudo, os órgãos de maior poder decisório do sistema de ensino. Esse é um elemento que depõe contra o discurso da descentralização no âmbito da gestão educacional, como também explicita o reducionismo do compartilhamento das decisões em nível de gerências administrativas do município.

Palavras-chave: Gestão compartilhada. Política educacional. Sistema Municipal de Ensino.

\section{Shared management education: the speech and the daily practices in the education system of the Recife}

\begin{abstract}
This article examines the issue of sharing of decisions in the management of public education, problematized the relationship between the discourse of democratic management and social practices of school counselors and managers of the Municipal System of Education of Recife. The data, collected through interviews and administration of questionnaires, were treated from the perspective of the analysis of speech. The goal is to collate certain concepts and characterizations of shared management, in the literature in the educational field,
\end{abstract}

* Professor da Universidade de Pernambuco - campus Garanhuns. Pernambuco, Brasil. 
and in interviews of research subjects, with the nuances surrounding the process of proposing educational policies for the city of Recife. It was concluded that the actions of the subjects that could contribute to the realization of democratic principles in the management of municipal education are slowing or silenced by a number of factors, among which stands out the disconnection between the institutions of participation. This proves that the difficulty of participation that is often singled out as strictly limiting the school, it is a problem that involves primarily the bodies of more decision making power of the education system. This is an element which then against the discourse of decentralization in the management education, but also explains the reductionism of the share of decisions at the level of administrative management of the municipality.

Keywords: Shared Management. Educational Policy. Municipal System of Education.

\section{Introdução}

Abordamos, neste artigo, aspectos relacionados ao processo de descentralização das decisões tanto no interior da instituição escolar quanto no contexto da definição das políticas educacionais para o município do Recife. O estudo é fundamentado no entendimento de que a gestão compartilhada da educação é um construto que ganha concretude através das relações que são estabelecidas entre as instâncias de participação do sistema de ensino nas quais os sujeitos envolvidos possam compartilhar desde o planejamento educacional até as práticas empreendidas no interior das unidades escolares.

Partindo deste juízo, tivemos como pergunta central do presente trabalho: a atuação dos sujeitos vinculados à gestão escolar transcende os limites da escola e corrobora a definição das políticas educacionais do sistema municipal de ensino?

Nossa coleta e categorização dos dados basearam-se na complementaridade entre o método quantitativo e o qualitativo, correspondendo, respectivamente: a) aos procedimentos da descrição de informações mais ampla sobre a participação da escola na definição das políticas educacionais, através de questionários aplicados em 78 escolas municipais, distribuídas nas Regiões Político-Administrativas do Recife, ${ }^{1}$ e b) a análise de discurso, por meio da interpretação de entrevistas semi-estruturadas realizadas em quatro escolas municipais, ${ }^{2}$ na Secretaria de Educação e no Conselho Municipal de Educação do Recife.

O texto é composto por três partes. Inicialmente, enfocamos o aporte teórico a partir do qual desenvolvemos a concepção de gestão compartilhada no contexto educacional. Em seguida, analisamos diferentes pontos de vista sobre 
a experiência do compartilhamento de decisões no interior da escola, e também no espaço ampliado do sistema de ensino do Recife. Por último, explicitamos nossas conclusões ao ressaltarmos as perplexidades, mas também as possibilidades de democratização quanto ao processo de planejamento e execução das políticas educacionais nesta municipalidade.

\title{
Gestão compartilhada da educação: sintonizando a ordem do discurso
}

O discurso da gestão compartilhada da educação é constituído e constituinte das relações que são estabelecidas nos diversos espaços em que as políticas educacionais são elaboradas e implementadas no âmbito do sistema de ensino. Esta perspectiva de gestão resguarda-se na formação discursiva que pressupõe o desenvolvimento de ações colegiadas, através das quais os sujeitos envolvidos possam compartilhar do planejamento educacional e das práticas empreendidas no chão da escola. Afirma Jamil Cury (2004, p. 55), que

\begin{abstract}
a gestão democrática pode ser lida por contraste com a gestão hierárquica [...] Ela expressa tanto a vontade de participação que tem se revelado lá onde a sociedade civil conseguiu se organizar autonomamente, quanto o empenho por reverter à tradição que confunde os espaços públicos com os privados.
\end{abstract}

Desta feita, ocupar o espaço público pelo diálogo significa conceber as instâncias de participação da gestão democrática (conselhos escolares e conselho municipal de educação, conferências, comissões representativas, etc.) como a via que torna possível tal princípio. Nesse sentido, a criação e a manutenção de suas atividades devem fazer parte das iniciativas tanto das instâncias locais quanto dos órgãos estrategicamente instituídos como locus decisório do sistema de ensino. É verdade que numa sociedade como a brasileira, marcada pelos vícios clientelistas e pela submissão ao argumento do mais forte, a prática dialogal soa sempre como uma utopia inatingível.

Não obstante, há um amplo consenso, por exemplo, sobre a instituição dos conselhos escolares como mecanismo de democratização da gestão escolar. Chama-nos a atenção o fato de que mesmo as pesquisas sobre a repercussão da ação dos conselhos nas unidades educacionais ainda não atestarem uma efetiva democratização da gestão (ANDRADE, 2006; CATANI; GUTIÉRREZ, 2003; BRANDÃO, 2002; WERLE, 2003; DOURADO, 2003), todavia não se contesta a relevância do conselho escolar como mecanismo de democratização.

O tema da participação popular no plano da intervenção na gestão educacional tem sido visitado por importantes pesquisadores do campo educacional (FARENZENA, 2006; MOTTA, 2003; CURY, 2004; MARTINS, 2002). O tipo da participação, o grau de intensidade que cada partícipe confere a suas ações no conselho escolar, a abrangência que a participação no colegiado es- 
colar alcança no interior do sistema de ensino, e o absenteísmo dos indivíduos na participação são alguns dos componentes temáticos presentes nos estudos sobre a ação colegiada na democratização da gestão educacional. Pode-se considerar que, regra geral,

\begin{abstract}
a participação de atores em processos de decisão institucional, seja no ambiente político ou no ambiente organizacional, tem sido condicionada pelo contexto histórico que molda os mecanismos de funcionamento desses processos. Acrescente-se que atores que convivem em cenários autoritários poderão, ainda, apresentar maior grau de dificuldade em expressar suas opiniões, em criar e mobilizar sua energia física e emocional para um empreendimento coletivo. (MOTTA, 1997, p. 201)
\end{abstract}

Isso significa que a afirmação de que os indivíduos simplesmente não estão tão sequiosos por participação não responde satisfatoriamente a questão da manutenção de práticas centralizadoras da gestão escolar e educacional. É preciso, como advertiu Motta (1997), observarmos o contexto em que os sujeitos estão inseridos. Faz-se necessário, inclusive, atentarmos para a análise do ambiente dos conselhos de educação e considerarmos os eixos temáticos da participação e compartilhamento das decisões a partir das relações de poder ali presentes.

Conforme registros da história recente do país, a possibilidade dos indivíduos voltarem a participar no espaço público brasileiro tem sido conquistada no período de pouco mais de duas décadas.

Portanto, é possível acatarmos que, em certos casos, o absenteísmo de alguns sujeitos pode significar até mesmo uma forma de se proteger. Conforme sabemos, parte considerável dos partícipes da ação coletiva nasceu e foi formada durante o regime de centralização. "De repente" os cidadãos se vêem na obrigação de se engajarem na luta sem que uma cultura democrática tenha sido radicada na sociedade, como pondera Cury (2004).

As fortes lembranças desse passado projetam marcas para o presente, ora revelando sujeitos receosos de participar das decisões, ora revelando indivíduos aguerridos, convictos de seu papel no processo de fortalecimento da democracia do país. Assim, se, por um lado, temos conhecimento de sujeitos que pertencem ao tipo de participação funcional, que constitui a "prática de reuniões periódicas entre patrões e trabalhadores, entre administradores, funcionários e trabalhadores, entre unidades organizacionais e entre níveis hierárquicos em geral" (MOTTA, 2003, p. 371), há outros indivíduos que se integram aos conselhos para defenderem projetos que favoreçam o coletivo em que está inserido. 


\section{Autonomia da escola: implicações na gestão do sistema de ensino}

A discussão sobre o termo autonomia pode nos levar a uma ampla possibilidade de seu entendimento, e sobretudo, de sua aplicação na relação da escola com os órgãos de maior poder decisório no sistema de ensino. Partindo desse entendimento, pretendemos evidenciar a questão do exercício da autonomia na e pela escola a partir de sua inter-relação com as instâncias sociais que estão envolvidas com a gestão educacional mais ampla, da qual a instituição escolar é parte. Barroso (2003) afirma que o conceito sob análise está ligado à idéia de autogoverno, na qual os sujeitos se regulam por regras próprias. Contudo, o autor também salienta que isso não é sinônimo de indivíduos independentes. Assim, "autonomia é um conceito relacional (somos sempre autônomos de alguém ou de alguma coisa) pelo que a sua ação se exerce sempre num contexto de interdependência e num sistema de relações" (BARROSO, 2003, p. 17).

Com efeito, não podemos discutir princípios para a implementação da gestão democrática à parte de suas implicações no que compreendemos por autonomia da escola. Assim, tanto não podemos conceber a escola independente em relação ao sistema de que faz parte, como também não há sentido reverenciarmos uma concepção de autonomia que se restringe às engenharias que as unidades de ensino desenvolvem na intenção de agilizar a implementação das decisões preestabelecidas pelas instâncias superiores do sistema de ensino.

Diante desses dois extremos, tomamos de empréstimo a concepção de autonomia de Castoriadis (1991, p. 140-148), no tocante a sua concepção de que a

autonomia é o agir reflexivo de uma razão, que se cria num movimento sem fim, ao mesmo tempo individual e social [...]. Autonomia é, portanto, o projeto, e agora estamos, ao mesmo tempo, no plano ontológico e no plano político que visa, no sentido amplo, ao nascimento do poder instituinte e sua explicitação reflexiva.

Nesse sentido, é pertinente a assertiva (GOMES; ANDRADE, 2007, p. 4) de que "a prática da autonomia não pode e nem deve ser auto-referente, mas referente ao contexto do sistema educativo do qual a escola é parte constituinte, e ao contexto social, político, econômico e cultural, no qual não apenas a escola está inserida, mas o próprio sistema de políticas educacionais". A relevância reconhecida a esse agir autonomamente se insere na perspectiva de uma autonomia escolar que é antes uma bandeira defendida à luz das convicções de cada sujeito envolvido com o processo educativo e depois uma construção coletiva da escola. 
Torna-se premente a reafirmação de que as escolas precisam se certificar da necessidade de se pensar a vivência da autonomia como conseqüência de seus próprios esforços; de suas reflexões no sentido da elaboração de um projeto político-pedagógico que aponte para o atendimento das especificidades de cada realidade escolar. Nessa afirmação, estamos tão-somente enfatizando a noção de autonomia construída por aqueles que a desejam e, evidentemente, nos afastando da adoção de uma postura passiva em que circunscreve a autonomia como decreto em leis, ou concessão das autoridades governamentais que representam o Estado.

Sendo assim, "o que está em causa é reconhecer a autonomia como um valor intrínseco à organização da escola, e utilizar essa autonomia em benefício das aprendizagens dos alunos" (BARROSO, 2003, p. 21). Portanto, pensar o exercício da autonomia do colegiado escolar implica considerar a sua capacidade política de intervir e de propor as políticas educacionais. Nesse movimento, a pluralidade do espaço discursivo deve respeitar as alteridades e as singularidades, ao mesmo tempo em que se concebe a interdependência como pressuposto fundamental da ação comunicativa entre o conjunto das instâncias que compõem a gestão do sistema de ensino.

\title{
O compartilhamento da gestão educacional no contexto do sistema de ensino do Recife
}

No que diz respeito às relações entre as instâncias de participação na gestão da educação municipal do Recife, a presidente do Conselho Municipal de Educação (CME) faz a seguinte colocação:

\begin{abstract}
o que precisa fortalecer é a representação do Conselho Escolar no CME. Então, se esse representado fizesse a articulação com os seus... Se esse conselheiro escolhido em assembléia pelos pais que compõe o Conselho Escolar, isso já foi uma decisão de que os representantes dos pais aqui no CME, ele é uma pessoa escolhida pelos pais dos conselhos escolares. Aí, eu não sei nem se os pais sabem disso. (Presidente do CME, entrevista realizada em 05 de junho de 2006)
\end{abstract}

Verifica-se que a presidente do CME justifica que os empecilhos para a materialização dos princípios democráticos dispostos nos textos dependem primordialmente do Conselho Escolar (CE). É possível inferir que, implicitamente, esta entrevistada concebe que a parte que cabe às instâncias superiores na mobilização por uma maior participação e, conseqüentemente, descentralização da gestão educacional, está sendo cumprida satisfatoriamente. Subtende-se, desse discurso que ou a contrapartida nasce da escola, ou então as demais instâncias não se prontificarão a cumprir os pressupostos da gestão compartiIhada. O depoimento a seguir pontua razoavelmente esta consideração: 
Gestão compartilhada da educação: o discurso e as práticas cotidianas no sistema de ensino do Recife

as comissões regionais só são viáveis, só são efetivas e-fe-ti-va-das se o CE estiver atuando na sua plenitude. Não é que a gente não reconheça. Ocorreram eleições pra comissões regionais, mas não aconteceram na prática. Elas não atuaram enquanto intercâmbio entre os conselhos e a secretaria, que esse é o objetivo principal. É uma questão de representação, mesmo. Quando um representante da comissão regional eleita ia até a escola chamar para uma discussão, eles não identificavam, ligavam pra cá, pra secretaria para saber. Essa é uma coisa da cultura, da mentalidade. (Técnico em Educação, entrevista realizada no Núcleo de Gestão Democrática em 09 de maio de 2006)

Essa concepção justifica, inclusive, parcialmente, o fracasso das Comissões Regionais de Educação. Durante nossas observações nas escolas, os conselheiros reclamavam insistentemente da falta de uma articulação regional. No entanto, essa articulação na prática parece só interessar a escola. Tanto a Secretaria de Educação quanto o CME não assinalam qualquer esforço para que as comissões regionais possam efetivamente funcionar.

É justo também ressaltar que as falas dos gestores, apesar de resguardarem-se na formação discursiva que ratifica o princípio da gestão democrática, as práticas sociais dão o tom, a partir do qual cada sujeito pretende justificar sua interpretação dos escritos sobre o processo de compartilhamento das decisões na gestão educacional. Por isso, aparecem as divergências dos argumentos entre os sujeitos no interior do Sistema Municipal de Ensino do Recife (doravante SMER). Analisemos, inicialmente, um extrato da entrevista com a ex-secretária de educação do Recife (2005-2008):

eu acho assim, na medida que você é uma gestão que foi eleita, isso eu estou falando de João Paulo, por exemplo, ele foi eleito por um projeto que tem outra perspectiva do que um outro projeto que não foi eleito. Então, isso tem que permear todas as ações que a gente faz na gestão. Quando você vai discutir, exatamente é essa linha tênue de você não ser considerado autoritário, que você diz: É assim porque é assim! Todo planejamento que a gente fez envolveu as oito diretorias - envolveu todas as gerências. A gente chegou a fazer reunião com 150 pessoas pra decidir o plano plurianual que vai até 2009. (Ex-secretária de educação, entrevista realizada em 29 de agosto de 2006, grifos do autor)

O discurso desta ex-secretária de educação, além de declarar o compromisso com a coerência interna na equipe do governo municipal, também alude a uma perspectiva de gestão com base da defesa do antiautoritarismo. Ainda assim, não é possível inferir, claramente, o ideário de uma ação articulada 
que considere a relevância da inter-relação entre a Secretaria de Educação e as demais instâncias do sistema municipal de ensino. Observemos que em sua fala a ênfase que é atribuída à construção do plano plurianual ressalta o encontro entre as diretorias que representam o próprio governo como algo que justifica, implicitamente, a perspectiva da construção compartilhada das decisões.

$\mathrm{Na}$ realidade, é justo reconhecermos que tal iniciativa de fato corresponde a uma prática fundada nos princípios democráticos, uma vez que o conjunto dos setores de um governo não constitui um bloco monolítico, portanto, a própria discussão com os representantes das diretorias deve ser interpretada como uma possibilidade de compartilhamento da decisão. Entretanto, o texto não chama a atenção para a necessidade de um debate com as outras instâncias de participação da gestão democrática, como o CME e os conselhos escolares. No conjunto da entrevista da secretária de educação observa-se que as referências sobre as práticas de compartilhar a decisão no âmbito do sistema de ensino são feitas com mais ênfase nas ponderações a respeito das dificuldades que o processo requer do que propriamente no sentido de reconhecer a implementação desse princípio como meta a ser alcançada, também, pelos gestores.

O ex-secretário adjunto de educação, que participou da gestão educacional do município do Recife durante os três anos iniciais do primeiro mandato do prefeito João Paulo (2001-2003), desenvolve o seguinte argumento sobre a concepção de gestão compartilhada:

\begin{abstract}
quando se é eleito com a apresentação de um programa, não é, há uma compreensão de uma aprovação tácita de determinação de programas. Lógico, a implementação dele está sujeita à correlação de forças, a pressão dos movimentos ou de outras forças políticas. Mas, eu acho que a compreensão sobre o projeto político vitorioso, quando se dá o momento de escolhas nas eleições, com a combinação disso com o arcabouço legal, e com a concepção que não está necessariamente no legal, mas está no projeto político do papel do poder público, do papel do Estado. Dito de uma maneira geral, é preciso construir uma gestão mais ampliada. (Ex-secretário adjunto municipal de educação, entrevista realizada em 01 de junho de 2006)
\end{abstract}

A fala do ex-secretário adjunto faz, inicialmente, menção ao projeto de governo democraticamente escolhido pelo povo como autorização da sociedade para que o governante possa implementá-lo de acordo com as suas concepções político-ideológicas. No entanto, sua colocação de que a implementação dos programas está sujeita à correlação de forças pressupõe uma relação que, necessariamente, reclama a discussão com o conjunto das instâncias de participação do SMER. 
A esse respeito, a fala do entrevistado também faz referência à construção de uma gestão mais ampliada como meta a ser alcançada. Faz-se importante informar que no conjunto de sua entrevista este ex-gestor referiu-se, enfaticamente, à imprescindibilidade das instâncias de participação para a materialização da gestão compartilhada. É ainda justo destacar que a leitura integral de seu texto permite a interpretação de que os esforços empreendidos pelos gestores no início do primeiro governo João Paulo voltaram-se para as ações de fortalecimento da articulação entre o governo e a sociedade civil, com ênfase na citação das instâncias que integram a gestão da educação municipal, como os conselhos escolares, o CME, as Comissões Regionais de Educação e a criação do Núcleo de Gestão Democrática com a finalidade de facilitar a comunicação entre as escolas e a Secretaria de Educação.

Observamos, também, os argumentos dos sujeitos participantes dos conselhos escolares. Percebemos uma ênfase, atribuída pelos conselheiros, às dificuldades de articulação com as demais instâncias do sistema de ensino. A esse respeito, tem-se uma avaliação convergente entre os conselheiros de que não há uma prática de compartilhamento do processo de decisões na gestão educacional do município. É o que revela o depoimento abaixo:

\begin{abstract}
eu acho assim, as coisas quando vem pra escola, elas já vêm determinadas. Ninguém procura antes saber, ou trazer pra que seja feita a discussão. Acho que é discutido entre eles lá, depois chega aqui pra gente implementar, tá entendendo? Não existe esse diálogo assim, tão aberto como se propaga por aí não. A coisa não é tão... Tem um lado mais amarrado. Nós nunca tivemos nenhuma visita, nenhum acompanhamento por parte do CME de jeito e maneira, também não procuramos eles. Não houve essa procura. (Direção da Escola Verão, entrevista realizada em 02 de julho de 2006)
\end{abstract}

Esse depoimento associa o problema da desarticulação entre as instâncias com o reconhecimento da cisão entre o planejamento e a execução das políticas na gestão do SMER. A fala desta representante do segmento direção é emblemática para o contexto mais amplo das entrevistas realizadas com os sujeitos da pesquisa. Isso significa que os conselheiros reconhecem, e argumentam em tom de protesto, o fato do momento da decisão ficar restrito aos órgãos de maior poder decisório do sistema, enquanto a responsabilidade da implementação é transferida para a escola.

\title{
Atuação do colegiado escolar no sistema municipal de ensino
}

Ao indagarmos os conselheiros escolares sobre a intensidade de suas relações com as instâncias do SMER, tivemos reiteradamente a resposta de que a ausência de uma instância de interlocução constitui um agravante significativo da frágil comunicação entre os conselhos escolares e também da relação 
destes com as instâncias superiores do sistema. Os dados quantitativos da pesquisa confirmam, expressivamente, a desarticulação entre os conselhos escolares, impedindo tanto a prática dialogal em nível de Região Político-Administrativa (RPA) da cidade, como o momento de discussão de acordos com o CME.

Observa-se que apenas $20,5 \%$ dos 78 conselhos escolares consultados conseguem articular-se com outros conselhos da mesma RPA. Este dado evidencia as dificuldades para o fortalecimento da ação colegiada para além dos limites da escola. Situações como a definição do calendário escolar, considerando-se não apenas a distribuição dos dias letivos, mas sobretudo a agenda da educação municipal para um determinado período letivo; a discussão sobre a formação continuada dos professores; a elaboração da matriz curricular que referencia a base comum, assim como os conteúdos programáticos e situações didáticas que atendam as demandas locais; reivindicação de melhores condições objetivas para o processo de ensino-aprendizagem nas unidades de ensino municipais, dentre outras, exigem uma ação integrada das instâncias de participação, sobretudo entre as próprias unidades de ensino.

Nesse mesmo sentido, perguntamos se o conselho escolar tem comunicado suas decisões a outras instâncias do SMER. Os conselheiros escolares de $52,6 \%$ das unidades de ensino pesquisadas revelam que raramente comunicam suas decisões às demais instâncias do sistema. Ao pontuarem os poucos momentos dessa comunicação, fazem menção às requisições da Secretaria de Educação e/ou do CME. Não são momentos efetivos de compartilhamento de decisões. Além disso, 23,1\% das escolas declaram que não comunicam nenhuma decisão ou proposta às demais instâncias da gestão educacional.

Ao correlacionarmos os dados categorizados no conjunto de nosso trabalho, identificaremos um quadro em que o discurso da gestão compartilhada fica restrito apenas ao nível dos textos elaborados pelos sujeitos que respondem pelas instâncias superiores do sistema de ensino. Numa gestão democrática, conforme já discutimos, as ações, os atos e os princípios são decididos e assumidos coletivamente por todos os sujeitos envolvidos com a gestão educacional. Consultamos, então, os conselhos escolares sobre suas avaliações a respeito das decisões que emanam da Secretaria de Educação e chegam à escola para serem implementadas.

O que se constata é que $62,8 \%$ dos conselhos consultados afirmam que discordam ou já discordaram das decisões que chegam para a escola implementar. Nossa interpretação é de que tal postura da escola cumpre as expectativas de um relacionamento democrático no qual o dissenso constitui parte inerente às relações dialógicas que se estabelecem entre as diferentes instâncias de participação. Entretanto, se faz necessário saber o que são feitos dos dissentâneos manifestos pela escola. Assim, o primeiro passo a ser exami- 
nado após a descrição de que as escolas dispõem de argumentos diferentes dos que são difundidos pela Secretaria de Educação é saber se a escola consegue socializar suas experiências, questão que trataremos na seqüência.

Observa-se que apenas 32,9\% dos conselhos consultados conseguem enviar suas discordâncias à Secretaria de Educação. Na realidade, dos 66 conselhos que responderam a esta questão, 67,1\% revelaram a ausência de qualquer contato estabelecido entre o CE e a Secretaria de Educação. Os dados evidenciam a desarticulação não apenas entre a escola e a Secretaria de Educação, mas também no que diz respeito à comunicação entre os conselhos escolares e o conjunto das instâncias do SMER. Há evidências de que o processo de compartilhamento das decisões não constitui uma prática social vivenciada entre à Secretaria de Educação e as escolas. Tal situação reflete a exclusão dos conselhos escolares nos momentos de planejamento e decisão das políticas educacionais. Nota-se que sobre a questão acima, $69,7 \%$ dos conselhos escolares responderam que não recebem qualquer resposta após enviarem seus dissensos a Secretaria de Educação. Esta constatação revela uma situação em que a Secretaria de Educação não articula suas decisões com os contrapontos que emanam da escola, isto porque apenas $3 \%$ dos conselhos responderam que sempre recebem respostas desta instância a respeito de seus dissensos. Tem-se ainda um percentual de $13,6 \%$ que raramente recebem respostas sobre seus contra-argumentos.

Sobre este último caso, os conselheiros justificaram, durante nossos contatos ao longo da pesquisa, que se trata de questões mais pontuais como a negociação de reposição de dias letivos por ocasião de greve. Nestes casos, a Secretaria de Educação responde as discordâncias da escola na intenção de reafirmar seus propósitos. Portanto, não se trata de uma discussão sobre o processo de decisão de questões mais amplas e inerentes às políticas educacionais que passam a nortear os processos educativos no âmbito municipal.

\section{Considerações finais}

Concluímos que a desarticulação entre as instâncias de participação constitui a principal causa da centralização do poder de decisão sob a égide da Secretaria de Educação. Isso é um indicativo de que a dificuldade de participação que freqüentemente é apontada como limitação estritamente da escola, trata-se de um problema que envolve, sobretudo, as instâncias superiores do sistema. Conforme revela os dados da pesquisa, os contatos entre o CME e a Secretaria de Educação não representam o elo entre o local e centro do sistema, uma vez que não há uma prática dialogal sistemática que autorize os conselheiros municipais falarem em nome dos segmentos das comunidades escolares de cada RPA. Esse é um elemento que depõe contra o discurso da descentralização no âmbito da gestão educacional, como também explicita o reducionismo do compartilhamento das decisões em nível de gerências administrativas do município. 
Constatamos, também, que as dificuldades para o exercício da autonomia não se restringem ao contexto dos conselhos escolares. O próprio CME também enfrenta fortes limitações quanto à sua intervenção na definição das políticas educacionais do município. Mesmo que se utilize o argumento da autonomia de seus partícipes, num apelo à postura exercida por parte de seus membros, não se pode relegar o fato de que sua voz não reflete o acordo com a base, o que facilita o pacto com as propostas da Secretaria de Educação e, conseqüentemente, a minimização dos momentos de dissensos característicos das relações democráticas.

Constata-se, no contexto da gestão escolar, a necessidade de realização de encontros por cada segmento do conselho escolar, em face de que $75,6 \%$ dos conselhos consultados declaram que não desenvolvem tal atividade. Este quadro ilustra a incoerência de se falar em representatividade quando os representados não tomam parte do que é proposto em nome do coletivo. Assim, acredita-se ser oportuno instigar iniciativas como a criação e funcionamento dos grêmios estudantis, que hoje existem apenas em 3,8\% das escolas consultadas, além da necessidade de se instigar os encontros de pais e mestres como parte do calendário escolar.

Dentre as atividades a serem desenvolvidas pelos conselhos escolares, faz-se necessário, também, a coordenação da formação continuada de seus membros. Constatamos que uma ampla maioria dos conselheiros declara o desconhecimento de suas funções como principal empecilho para uma atuação mais próxima do ideal.

No âmbito da gestão do sistema de ensino, propomos uma reorganização das instâncias de participação na perspectiva de que o processo de discussão e deliberação das políticas educacionais do município possa integrar a participação dos sujeitos vinculados à educação pública municipal em todos os seus setores. Assim, entendemos que o atual organograma da gestão educacional, em que se verifica a postura da Secretaria de Educação como centro do sistema de ensino, em detrimento do papel periférico exercido pelo conselho escolar, precisa ser repensado, considerando-se a necessidade de ativação dos mecanismos de interlocução no interior do sistema como principal contrapartida em favor do avanço no processo de compartilhamento da decisão política em nível municipal.

\section{Referências}

ANDRADE, E. F. O papel dos Conselhos Escolares no Sistema Municipal de Ensino do Recife. Gestão em Ação. Salvador, v. 9, n. 3, p. 351-366. set./dez. 2006. Disponível em: <http://www.gestaoemacao.ufba.br>. Acesso em: 26 ago. 2008. 
BARROSO, J. O reforço da autonomia das escolas e a flexibilização da gestão escolar em Portugal. In: FERREIRA, N. S. C. (Org.). Gestão democrática da educação: atuais tendências, novos desafios. São Paulo: Editora Cortez, 2003.

BRANDÃO, C. R. Soletrar a letra P: povo, popular, partido e política - a educação de vocação popular e o poder de Estado. In: FÁVERO, O; SEMERARO, G. (Orgs.). Democracia e construção do público no pensamento educacional brasileiro. Rio de Janeiro: Editora Vozes, 2002.

BRASIL. Constituição da República Federativa do Brasil. Brasília, 1988.

BRASIL. MINISTÉRIO DE EDUCAÇÃO E CULTURA. Lei n. 9394/96 Lei de Diretrizes e Bases da Educação Brasileira. Brasília: 1996.

CASTORIADIS, C. A Instituição imaginária da sociedade. Rio de Janeiro: Paz e Terra, 1991.

CATANI, A. M; GUTIÉRREZ, G. L. Participação e gestão escolar: conceitos e potencialidades. In: FERREIRA, N. S. C (Org.). Gestão democrática da educação: atuais tendências, novos desafios. São Paulo: Editora Cortez, 2003.

CURY, C. R. J. Os Conselhos de Educação e a Gestão dos Sistemas. In: FERREIRA, N. S. C. \& AGUIAR, M. A. S. Gestão da Educação: impasses, perspectivas e compromissos. 4 ed. São Paulo: Cortez, 2004.

DOURADO, L. F. A escolha de dirigentes escolares: políticas e gestão da educação no Brasil. In: FERREIRA, N. S. C.(Org.). Gestão democrática da educação: atuais tendências, novos desafios. São Paulo: Cortez, 2003.

FARENZENA, N. Descentralização e Federalismo: algumas implicações para as responsabilidades (inter) governamentais no financiamento da Educação Brasileira. In: PERONI, V; BASSO, V; COSTA, A. Dilemas da e•educação brasileira em tempos de globalização neoliberal. Porto Alegre: Ed. UFRGS, 2006.

GADOTTI, M. R. J. E. Autonomia da escola princípios e propostas. 2. ed. São Paulo: Cortez: 1997.

GOMES, A. M; ANDRADE, E. F. Autonomia da escola: dimensões e contradições no sistema municipal de Recife. In: Encontro de Pesquisa Educacional do Norte Nordeste, 2007, Maceió. Política de Ciência e Tecnologia e Formação do Pesquisador em Educação, 2007.

MARTINS, A. M. Autonomia e educação: a trajetória de um conceito. Cadernos de Pesquisa, São Paulo, n. 115, p. 207-232, março, 2002. Disponível em: <http://www.scielo.br/scielo.>. Acesso em: 26 ago. 2008.

MOTTA, F. C. P. Administração e participação: reflexões para a educação. Educação e Pesquisa, São Paulo, v. 29, n. 2, p. 369-373, jul./dez. 2003. Disponível em: <http://www.scielo.br/scielo > Acesso em: 26 ago. 2008. 
MOTTA, F. C. P; CALDAS, M. P. (Org.). Cultura organizacional e cultura brasileira. São Paulo: Atlas, 1997.

WERLE, F. O. C. Conselhos Escolares: implicações na gestão da Escola Básica. Rio de Janeiro: DP\&A, 2003.

Notas

1 Conforme Lei Municipal n. 16.293/1997, o Município do Recife é dividido em seis Regiões Político-Administrativas - RPAs, para efeito de formulação, execução e avaliação permanente das políticas e do planejamento governamentais. Está prevista uma sede regional para cada RPA, onde poderão ser instaladas as unidades administrativas desconcentradas dos diferentes órgãos da Prefeitura da Cidade do Recife, para os fins previstos no Plano Diretor de Desenvolvimento da Cidade do Recife, observadas as normas legais e regulamentares pertinentes.

2 Utilizamos os nomes das estações do ano para identificarmos as escolas que compuseram nosso campo de pesquisa. As duas escolas da Região Político-Administrativa (RPA) 06 receberam os codinomes Escola Verão (EV) e Escola Primavera (EP). Já as escolas da RPA 04 atendem por Escola Outono (EO) e Escola Inverno (EI).

\section{Correspondência}

Edson Francisco Andrade - Rua Capitão Pedro Rodrigues, 105, São José, CEP 55.294-902, Garanhuns (PE).

E-mail: edsonprofessor@uol.com.br

Recebido em 26 de outubro de 2008

Aprovado em 21 de setembro de 2009 